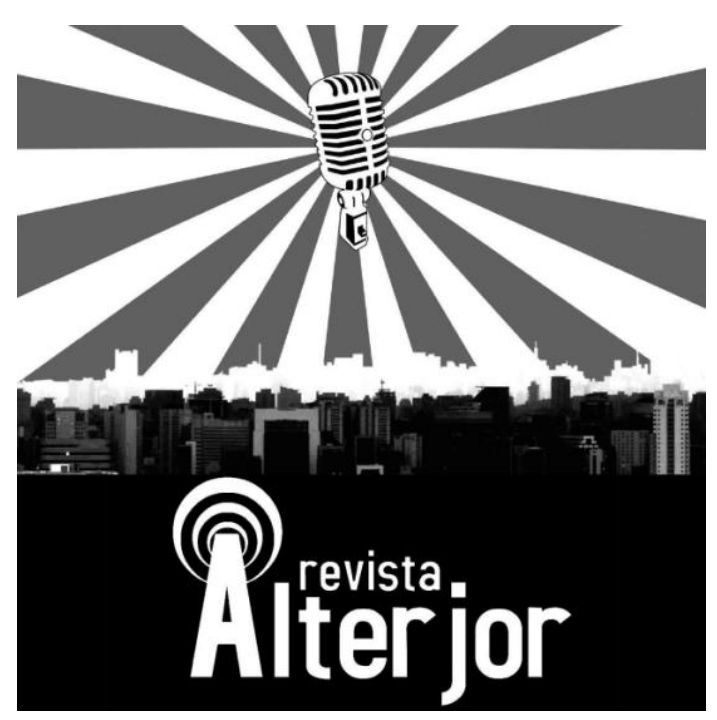

\title{
POLÍTICAS DE COMUNICAÇÃO, PRÁTICAS COMUNICACIONAIS E AÇÕES DE RESISTÊNCIA: QUANDO COMUNIDADE, CULTURA E IDENTIDADE ENTRAM EM CENA
}

\author{
João Eudes Portela de Sousa ${ }^{1}$
}

\begin{abstract}
RESUMO: O estudo faz uma reflexão sobre as políticas de comunicação no Brasil, analisando como se estabeleceu esse cenário que tem se configurado em um jogo político e pouco democrático. O descompasso comunicacional tem interferido na produção, acesso e disseminação de mensagens que apresentem a pluralidade cultural brasileira. Observa-se uma ausência de investimentos, legislações e descaso público ao gerir estratégias que minimize lacunas das áreas de comunicação e mídia no Brasil. O cenário se caracteriza pela falta de espaços que promovam à diversidade cultural de sujeitos e sociedades, enquanto comunidades tentam amenizar essa realidade produzindo conteúdos em espaços virtuais minimizando essa falta de representatividade com o intuito de (re)construir uma sociedade culturalmente mais plural e democrática.
\end{abstract}

PALAVRAS-CHAVE: Políticas de comunicação. Cultura. Identidade. Tianguá.

ABSTRACT: The study reflects on communication policies in Brazil, analyzing how this scenario was established, which is defined in the political and undemocratic game. The communicational gap has an impact on the production, access and dissemination of messages that present a Brazilian cultural plurality. Observe an absence of investment, legislation and public neglect when managing strategies that minimize gaps in the areas of communication and media in Brazil. The scenario is characterized by the lack of spaces that promotes the cultural diversity of societies and societies, while communities try to soften this reality produced in public spaces, minimizing this lack of representativeness in order to (re) create a more culturally plural and democratic society.

KEYWORDS: Communication policies. Culture. Identity. Tianguá.

\footnotetext{
${ }^{1}$ Docente Efetivo do Instituto Federal de Educação, Ciência e Tecnologia do Estado do Ceará (IFCE) e doutorando no programa de pós-graduação em Comunicação e Linguagens da Universidade Tuiuti do Paraná (UTP). E-mail: joaoportelas@gmail.com
}

Revista ALTERJOR

Grupo de Estudos Alterjor:Jornalismo Popular e Alternativo (ECA-USP)

Ano 10 Volume 02 Edição $22 \quad$ Julho-Dezembro de 2020

Avenida Professor Lúcio Martins Rodriģues, 443, Cidade Universitária, São Paulo, CEP: 05508-020 


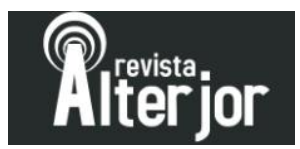

\section{INTRODUÇÃO}

Com o advento da internet, práticas digitais possibilitadas pelo desenvolvimento tecnológico transformaram as relações dos sujeitos nos mais diferentes campos. O século XXI tem sido marcado por uma explosão mediática jamais vista, são ações propostas por uma gama de meios de comunicação que emergem em dispositivos e plataformas na medida em que são acessados e compartilhados em alta velocidade.

No campo acadêmico, pesquisas tentam entender como isso reflete na cultura local, como essa globalização da informação interfere em políticas comunicacionais, práticas culturais e democratização da comunicação em comunidades menores. Para alguns teóricos como Marshall McLuhan (2006), defendem em seus estudos uma tese revelando que,

[...] o meio é a mensagem. Isto apenas significa que as consequências sociais e pessoais de qualquer meio - ou seja, de qualquer uma das extensões de nós mesmos - constituem o resultado do novo estalão introduzido em nossas vidas por uma nova tecnologia ou extensão de nós mesmos". (MCLUHAN, 1964; p.21).

A partir dessa perspectiva, pode ser perceber que os meios trazem um impacto na vida dos sujeitos, e nessa contemporaneidade as mensagens propriamente se caracterizam de forma bem mais descentralizada.

Dito isso, influenciados ou não pelos estudos da Escola de Toronto, o processo comunicacional deve ser encarado para além de um paradigma linear. Se pensarmos na atual conjuntura com a popularização dos novos meios de comunicação, surge uma mistura, uma fusão das antigas e novas mídias caracterizando essa sociedade contemporânea em uma era da convergência.

Segundo os estudos de Henry Jenkins (2009) essa convergência seria um "fluxo de conteúdos através de múltiplas plataformas de mídia, à cooperação entre múltiplos mercados midiáticos e [...] comportamento migratório dos públicos dos meios de comunicação (JENKINS, 2009: 29), essas novas práticas socioculturais têm emergido em diferentes plataformas "driblando" os grandes conglomerados midiáticos. 


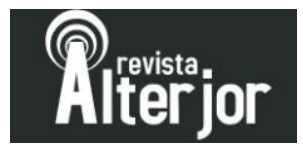

O que essa era digital tem proporcionado - são novas experiências, ações compartilhadas que ganham mais espaços na medida em que a sociedade tecnologizada se apropria de recursos para construir/produzir mensagens que migram dos meios tradicionais para as práticas comunicacionais da contemporaneidade, os novos paradigmas revelam experiências que acontecem em larga escala e ao longo alcance, e esse estudo revela que os meios digitais disseminam práticas culturais locais para um cenário global.

As mensagens construídas com a voz da comunidade, por agentes da cultura local, com temáticas culturais que anteriormente não encontrava espaço em programas de televisão, rádio, em jornais, nesse formato digital, bem com em redes sociais digitais são construídas e disseminadas por qualquer sujeito, em qualquer lugar e a qualquer momento - só precisando estar conectado à internet. Os sujeitos estão vivenciando um cenário de imersão, uma multiplicidade de meios comunicacionais que fornecem elementos para produções e circulações de mensagens.

Os meios eletrônicos têm atraído a atenção dos sujeitos, porém os meios analógicos sobrevivem e podem colaboram nessa transformação da comunicação global permitindo uma relação mais conectada dentro desse ecossistema mediático. O presente estudo, faz-se uma breve observação das práticas culturais e ações afirmativas a partir do consumo da tanajura na comunidade de Tianguá.

Nessa pesquisa, observamos como essa prática sociocultural que surgiu desde os primeiros habitantes indígenas tem se perpetuado por mensagens disseminadas em meios de comunicação, como a comunidade têm se apropriado (ou não) das políticas comunicacionais e se adequado aos meios de comunicação seja em veículos de comunicação tradicionais ou em meios digitais, em uma disputa por representação em caráter de resistência enquanto identidade cultural.

\section{POLÍTICAS DE COMUNICAÇÃO: SEGREGAÇÃO E DEMOCRATIZAÇÃo}

No Brasil existe uma ausência de regulamentações que possa promover espaços que democratizem o acesso à comunicação. Com isso, o que se reflete é uma concentração comunicacional que foi construída por diversos fatores ao longo dos anos 


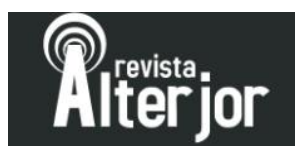

na história da comunicação brasileira. Esse modelo que tem como característica centralizada se fortaleceu nesse cenário ausente de políticas de comunicação.

Segundo o boliviano Luiz Ramiro Beltrán (1997), políticas de comunicação na mais é que "um conjunto de normas integradas e duradouras para reger a conduta de todo sistema de comunicação de um país, entendendo por sistema a totalidade das atividades de comunicação massiva ou não massiva" (BELTRÁN, apud GOMES, 1997: 107). Entretanto, o modelo que se fortaleceu por aqui no período do regime militar e ainda é usado até os dias de hoje, é bem diferente dos praticados em outros países, pois em outras nações logo após a fase de ditadura (similar à que aconteceu no Brasil), houve uma reestruturação no campo das políticas de comunicação e mídias.

Conforme Cesar Bolaño e Valério Brittos (2008) por aqui não se percebeu nenhuma mudança profunda nesse cenário comunicacional. O campo das concessões da radiodifusão no Brasil, que acontece entre o poder público e empresas privadas de comunicação é uma espécie de moeda de troca. Um exemplo disso é o que tem acontecido na contemporaneidade, a Rede Record e o Sistema Brasileiro de televisão (SBT) não têm a maior audiência, mas como apoiam o governo de Jair Bolsonaro (atual presidente do Brasil), recebe a maior fatia de investimentos com publicidade e propaganda do governo federal.

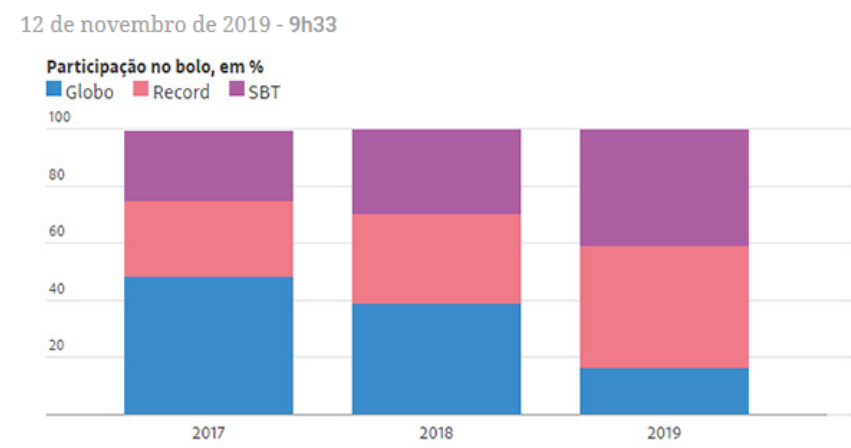

Gráfico 1: Dados da Secretaria de Comunicação Social da Presidência. Fonte: meio e mensagem

O governo de Fernando Henrique Cardoso até ensaiou uma moralização nas questões relacionadas às outorgas das concessões, estabelecendo alguns critérios como a licitação para concorrer às concessões, mas o que se perpetuou foi a flexibilidade na 


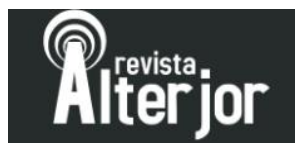

legislação vigente para essa área. No Brasil, as empresas privadas de comunicação ainda detêm um certo domínio na construção da opinião pública e qualquer tentativa de regular esse setor parece que acontece de forma lenta, já que os detentores desse mercado não demonstram nenhum interesse em renovar essas leis, mesmo observando que hoje são tidas como ultrapassadas para esse novo paradigma que é o sistema comunicacional. Para Octavio Pieranti (2006):

"O oferecimento de concessões sempre foi usado como importante moeda de troca pelos mais diversos governos brasileiros. Nessas barganhas, saíram favorecidas as grandes redes, que viram aumentar o número de emissoras afiliadas e o grau de cobertura de sua programação" (PIERANTI, 2006: 108).

Entretanto, nos últimos governos de Lula (2003-2010) e Dilma (2011-2016), algumas alterações foram construídas para essa dificultosa reformulação, alguns ajustes pontuais como a aprovação da lei $\mathrm{n}^{\mathrm{o}} 12.485 / 2011^{2}$, tido como um marco para o campo da regulamentação da TV paga no país o trouxe para a pauta mais conteúdos nacionais, fortalecendo as empresas nacionais de comunicação. Entretanto, esses avanços aconteceram somente na TV fechada, a TV aberta que é a mais assistida e acessível aos brasileiros não ocorreu.

Com a ausência de uma reformulação na legislação da TV aberta no país, questões como pluralidade cultural e representações identitárias ocorrem desde sempre de forma limitada. Não existe uma preocupação em representar povos e comunidades, não se atentam parra (re) formular uma programação que contenham o mínimo de representatividade e diversidade cultural, a perpetuação desse sistema comunicacional que está vigente é uma reafirmação diária dos fascismos sociais que estão cristalizados no nosso imaginário cotidiano brasileiro.

É nessa perspectiva que Armand Matterlart (2007) nos questiona: "como implantar uma política cultural pela diversidade cultural se a política de comunicação

\footnotetext{
${ }^{2}$ Dispõe sobre a comunicação audiovisual de acesso condicionado; altera a Medida Provisória no 2.228-1, de 6 de setembro de 2001, e as Leis $\mathrm{n}^{\mathrm{o}} \mathrm{s} 11.437$, de 28 de dezembro de 2006, 5.070, de 7 de julho de 1966, 8.977, de 6 de janeiro de 1995, e 9.472, de 16 de julho de 1997; e dá outras providências. Disponível em http://www.planalto.gov.br/ccivil_03/_Ato2011-2014/2011/Lei/L12485.htm> Acesso em 10/12/2019
} 


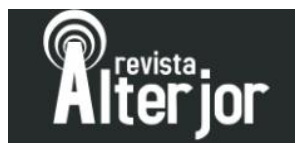

tira das mãos da sociedade as ferramentas e tecnologias para exercer seus direitos?" (MATTELART, 2007 apud YODA, 2007, s/p). O que temos visto é que a legislação vigente não corrobora para a construção de uma sociedade mais democrática, os meios comunicacionais massivos estão nas mãos de poucos que parecem não levar em consideração pautas que promovam relações de respeito e tolerância intercultural.

É nesse cenário de inquietações e descontentamentos relacionados à forma como o governo tem (ou não) construído as regulamentações das empresas de comunicação no país, que a sociedade civil tem se articulado e promovido espaços de discussões e debates acerca desse tema. O Fórum Nacional pela Democratização da Comunicação (FNDC) tem promovido alguns debates com pautas que trazem esses questionamentos, foram feitas algumas ações apresentando ideias sugerindo projetos de leis que amenizem desigualdades étnicas, gêneros, classe social, etc.

Às vezes parece que os gestores não percebem ou fingem não ver que que a sociedade mudou, que as práticas sociais e suas representações se reconfiguraram. Os governantes devem se atentar para as questões atuais; o que temos presenciando nessa contemporaneidade são modelos praticados anteriormente que não se enquadram nos dias atuais, o Brasil precisa perceber que é necessário o uso de novas medidas que regulamentem os tradicionais, mas também os novos meios de comunicação em atividade no país. Vale salientar que, o rádio e a televisão devem democratizar seu acesso e conter em suas programações uma pluralidade cultural existente e coerente com essa nação.

O coletivo Fórum Nacional pela Democratização da Comunicação (FNDC) mencionado acima, traz alguns questionamentos em seus discursos que podem nos ajudar a amenizar esses problemas, vejamos:

Como o índio, o negro, as mulheres, os homossexuais, o povo do campo, as crianças, aparecem na televisão brasileira? Como os cidadãos das diversas regiões, com suas diferentes culturas, etnias e características são representados? A liberdade de expressão não deveria ser para todos e não apenas para os grupos que representam os interesses econômicos e sociais de uma elite dominante? Existem espaços para a produção e veiculação de conteúdos dos diversos segmentos da sociedade na mídia brasileira? (FNDC, 2013, s/p) 


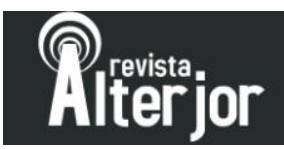

O que o coletivo propõe em seu projeto, nada mais é que: pautas que promovam e incentivem uma programação mais diversificada nas televisões brasileiras, que suas programações sejam mais heterogêneas e diversificada. A ideia é trazer pautas locais para o debate e que emissoras locais ocupem em sua grade produções regionais, que seja proibido a veiculação e apologia aos discursos de ódio nacional, de crença, racial, a violência "ou qualquer outra ação ilegal similar contra qualquer pessoa ou grupo de pessoas, por nenhum motivo, inclusive os de raça, cor, etnia, gênero, orientação sexual, religião, linguagem ou origem nacional" (FNDC, 2013: 9).

É importante promover uma reflexão a respeito da democracia da comunicação e como quebrar essa barreira, tendo em vista que existe uma ausência de políticas culturais e as políticas de comunicação não promovem uma diversidade cultural. O que parece é que o estado subtrai dos sujeitos e da sociedade as ferramentas para auxiliar em prol de um espaço mais livre e democrático. Os governantes não se preocupam em promover um espaço plural, uma vez que não possibilitam o acesso dos sujeitos aos veículos de comunicação como rádios, televisões que estão nas mãos dos grandes empresários. Os sujeitos tentam burlar esse sistema se apropriando de sites e redes sociais digitais para promover sua identidade cultural, porém o acesso a internet não ocorre para todos.

\section{PRÁTICAS COMUNICACIONAIS E AÇÕES AFIRMATIVAS EM TIANGUÁ (CE)}

Parece ter ficado de lado a verdadeira importância da democratização da comunicação no Brasil e o acesso dos veículos por parte da comunidade civil. O que se pôde perceber ao longo dos anos, foi o crescimento e a força dos grandes conglomerados comunicacionais; não só os voltados para as áreas gráficas como revistas e jornais, mas também os do segmento audiovisual como a televisão e rádio, estes, tomaram ferramentas de proporções gigantesca no campo da informação no país.

Pode ser vista como um descaso essa ausência de ações afirmativas que se preocupem de fato com políticas comunicacionais voltadas para as áreas educacionais e culturais. É perceptível que os veículos de comunicação brasileiros não atuam em prol 


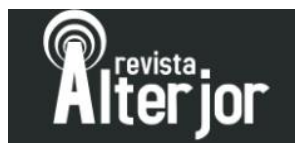

da sociedade em diversos segmentos, principalmente em questões relacionadas à diversidade cultural e na luta em prol da diminuição das diferenças sociais. Segundo José Marques de Melo:

\begin{abstract}
A expansão dos veículos eletrônicos na América Latina não alterou substancialmente a situação de analfabetismo e de carência cultural das classes trabalhadoras. O que provocou de imediato foi a difusão do consumismo, pois a publicidade comercial engenhosamente usou o rádio e a televisão para impingir os produtos supérfluos que as empresas multinacionais passaram a produzir na própria região. (Marques de Melo, apud Gomes, 1997: 114)
\end{abstract}

Dito isso, podemos ilustrar este caso lembrando de como isso tem ocorrido no Brasil até os dias de hoje. As concessões de rádio e televisão por aqui são distribuídas pelo Estado que se utiliza de um critério nada técnico, o favorecimento político. Esse critério tem como método principal agraciar os correligionários e os parceiros do governo, o que para alguns estudiosos da área de comunicação, essa ação é compreendia como um coronelismo eletrônico.

Vejamos, se a comunicação tem um poder de estreitar os laços, romper barreiras e encurtar fronteiras, porque não se apropriar dessa organização social que a comunicação promove enquanto formadora de opinião e estabelecer uma política comunicacional coerente e atuante. A comunicação como uma forma de educação pública, dialogando com diferentes áreas, promovendo um debate democrático entre sociedade e poder público não faria mais sentido? São aspectos como estes que devem ser levado em consideração para a construção de uma comunicação mais participativa e democrática.

O que não conseguimos identificar de forma clara e objetiva, são investimentos do governo que facilitem sujeitos locais, pessoas da comunidade a se aproximarem dos veículos de comunicação, principalmente daqueles tidos como massivos (televisão e rádio).

Parece ser algo muito complicado fazer com que assuntos locais e pautas regionais ganhem espaço nesses meios sem ser objeto de luta. "A originalidade da televisão é de poder fazer as duas coisas: ser um elemento de laço social no seio de uma 
comunidade nacional e um elemento de comunicação entre as diversas identidades nacionais" (WOLTON, 1996: 294). Porém, as comunidades têm ficado a mercê e muitas vezes consumindo bens simbólicos, produtos culturais de sociedades hegemônicas, adquirindo hábitos e reproduzindo padrões que desmerecem sua cultura. Essas ações tornam mais atraente e faz mais comum práticas e hábitos de outras culturas, os que são oriundas da sua origem os fazem parecer algo arcaico e ultrapassado.

Esconder-se por trás dos 'bons' resultados de 'maus' programas só comprova uma coisa que sempre soubemos: é mais fácil jogar os cidadãos e espectadores para baixo do que para cima. E se o público assiste a maus programas dizem menos sobre os públicos do que sobre a representação que se fazem aqueles que os produzem e difundem. Em resumo, digam-me quais os programas assistidos e eu lhes direi qual a concepção de público que existe na cabeça dos que os produziram (WOLTON, 1996: 15).

No município de Tianguá (CE) sujeitos tentam furar o "bloqueio" comunicacional, sendo este derivado da ausência de políticas comunicacionais, buscando seu espaço de voz em uma luta constante por um lugar de fala para se sentirem representado em narrativas que ressaltem sua identidade, sua cultura. Todavia, a construção de uma identidade é peça basilar de um povo para que se forme uma ideia de grupo e que os fortaleça em um entendimento enquanto sociedade.

Para esse conceito, tomamos como base os estudos de Stuart Hall (2014) que compreende,

O termo "identidade" para significar o ponto de encontro, o ponto de sutura, entre, por um lado, os discursos e as práticas que tentam nos "interpelar", nos falar ou convocar para que assumamos nossos lugares como os sujeitos sociais de discursos particulares e, pó outro lado, os processos que produzem subjetividades, que nos constroem como sujeitos aos quase se pode "falar". As identidades são, pois, pontos de apego temporário às posições-de-sujeito que as práticas discursivas constroem para nós. (HALL, 2014: 111-112)

A escritora Vânia Vasconcelos é uma nativa de Tianguá (CE) que promove ações culturais com dimensões comunicacionais na comunidade de Tianguá (CE). Suas atividades disseminam mensagens relacionadas à cultura e identidade local, a partir daí, 


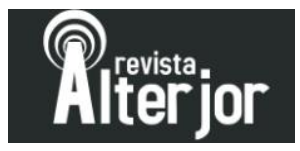

tem ganhado espaço para trazer pautas relacionadas a comunidade em veículos de comunicação da região.

O município de Tianguá (CE) nas últimas décadas tem se destacado por mensagens que circulam em rede retratando elementos inerentes da cultura local, um destes é o consumo da formiga tanajura (içá). Essa alimentação que é tão genuína da região tem despertado curiosidades em outros sujeitos a partir de práticas comunicacionais disseminadas principalmente em redes sociais digitais que evidenciam essa manifestação cultural.

Vânia Vasconcelos tem trazido essa pauta local para debates em diferentes espaços. A escritora tem se apropriando dos costumes e hábitos do seu povo para revelar para a sua e outras comunidades a cultura da sua gente através da literatura. Seja em feiras escolares da sua cidade ou em outros municípios, as narrativas promovem diálogos que aproximam os sujeitos (locais e de outras comunidades) das práticas socioculturais da sua comunidade. Suas histórias trazem para o debate práticas sociais e culturais inerentes de uma comunidade no interior do Ceará.

Figura 1: criança com o livro

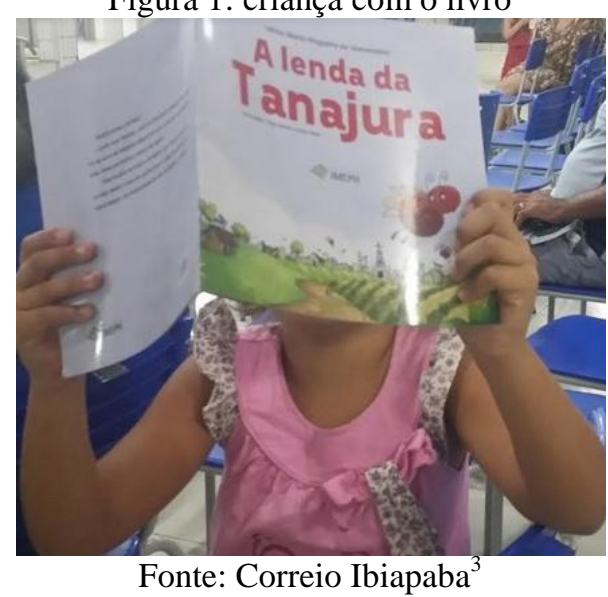

Em entrevista para o portal de notícias Correio Ibiapaba a escritora revelou seu interesse para com a literatura, a ideia é que seus livros retratem manifestações culturais, reafirmem cultura e identidade local e alcancem o maior número de pessoas. Para além de feiras e eventos literários, espaços como o rádio local (a escritora acredita

\footnotetext{
${ }^{3}$ Disponível em https://www.correioibiapaba.com.br/. Acesso em 02/02/2020. 


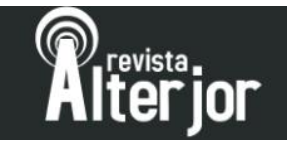

no alcance deste veículo para a divulgação da sua obra) tem sido usado para divulgar sua obra e pulverizar os sujeitos com assuntos inerentes ao seu espaço.

A identidade nacional, qualquer que seja ela, ou ainda que composta de múltiplas identidades, só se define no confronto com as identidades externas, de outros povos, outras nações. Não se trata, pois, de "fechar portos" abertos desde 1808, mas de estabelecer "controles alfandegários", que harmonizam a convivência de todos os influxos culturais, internos e externos. É isso que permitirá ao Brasil um sistema audiovisual equilibrado e uma inserção altiva no mercado globalizado da televisão (PRIOLLI, 2000, p. 23).

$\mathrm{Na}$ ausência de espaços em programas televisivos ou em emissoras de rádios de maior audiência (pois assuntos como esse raramente entram em pauta) a escritora visita escolas, na oportunidade passou pelo colégio Liceu de Tianguá (CE) onde existe um projeto de rádio escolar. Esse projeto que acontece toda às sextas-feiras ocorre da seguinte forma, é selecionado um livro que deverá ser lido na hora do intervalo. Porém, a transmissão acontece somente dentro da escola, não ultrapassando as paredes do colégio.

A televisão é muito mais do que um aglomerado de produtos descartáveis destinados ao entretenimento da massa. No Brasil, ela consiste num sistema complexo que fornece o código pelo qual os brasileiros se reconhecem brasileiros. Ela domina o espaço público (ou a esfera pública) de tal forma que, sem ela, ou sem a representação que ela propõe do país, torna-se quase impraticável a comunicação - e quase impossível o entendimento nacional (BUCCI, 1996: 9).

A autora também levou sua obra: a lenda da Tanajura para ser apresentada em um programa chamado "projeto hora da leitura" na rádio serrana - uma emissora de rádio local que alcança a zona urbana e rural do município, a ideia desse programa é entrevistar escritores que em grande parte são da cidade e promove uma participação com ouvintes. 


\section{Diriejor}

Figura 2: Vânia Vasconcelos em uma escola municipal.

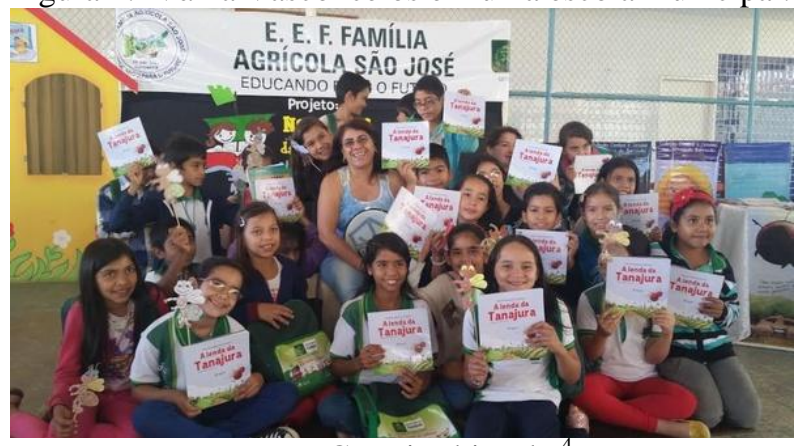

Fonte: Correio Ibiapaba ${ }^{4}$

Contudo, com a ausência de políticas de comunicação, escritores, produtores de conhecimento, guardiões da cultura local, dentre outros se debruçam para perpetuar saberes, hábitos, costumes e competências locais. Alguns sujeitos de Tianguá (CE) se destacam por promover à cultura local usando dos mais diferentes meios de comunicação para que o conhecimento, o acesso à informação chegue ao maior alcance possível.

Num país como o Brasil, em que a TV redefiniu o espaço público e reconfigurou a própria face da nacionalidade, a presença dos meios de comunicação é um fator incontornável para os educadores. (...) Isso, para a população que lê pouco, dá à TV uma condição de monopólio da informação, ou seja, a TV monogola sem que outros lhe façam contraponto (BUCCI, 2000, p. 9).

Visto que, com a dificuldade em virar pauta nas grades emissoras do estado, mesmo com poucos recursos e falta de incentivos, podemos perceber que manifestações em prol da comunicação cultural vêm se desenvolvendo na comunidade. Algumas produções audiovisuais retratando elementos da cultura local tem se proliferado, e uma época denomina por Henry Jenkins (2008), como a era da convergência, sujeitos têm se apropriado das tecnologias digitais para produzirem conteúdo e circular mensagens em diferentes plataformas.

Segundo Jenkins (2008) “a convergência representa uma transformação cultural, à medida que consumidores são incentivados a procurar novas informações e fazer

${ }^{4}$ Disponível em https://www.correioibiapaba.com.br/. Acesso em 02/02/2020.

Revista ALTERJOR

Grupo de Estudos Alterjor: Jornalismo Popular e Alternativo (ECA-USP)

Ano 10 Volume 02 Edição $22 \quad$ Juho- Dezembro de 2020

Avenida Professor Lúcio Martins Rodrig̉ues, 443, Cidade Universitária, São Paulo, CEP: 05508-020 


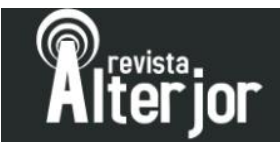

conexões em meio a conteúdos de mídia dispersos (JENKINS, 2008: 29), se antes as pautas locais não se encaixavam na grade da programação da televisão ou do rádio, com as mídias socias digitais a temática tem ganhado espaço de fala, novos olhares surgem nesse horizonte.

Ao acessarmos aa redes sociais digitais facebook, instagram ou youtube encontraremos alguns matérias produzidas de forma amadora retratando a prática da caça às tanajuras em Tianguá (CE), o que para Álvaro Laranjeira, Moisés Cardoso e Alexndre Kumm (2016: 140) "As redes sociais digitais são fundamentalmente diferentes de qualquer mídia tradicional por causa de sua estrutura e natureza igualitária", qualquer um pode produzir conteúdo. Com a democratização na produção e circulação das mensagens que as mídias digitais propuseram, surgiram temáticas que antes não se "encaixavam" nos meios de comunicação de massa e só agora ganham destaque ao serem pautadas primeiramente nas novas mídias para em seguida conseguir espaço nos grandes veículos de comunicação.

Na contemporaneidade uma matéria circula facilmente por várias mídias, você disponibiliza em um site, que se conecta ao mesmo tempo com o instagram, que pode ser compartilhado com o facebook e ter um link que a direcione para o youtube. Essa era da convergência: "desafiará formas estabelecidas de organização em vários domínios, desde a produção política até a produção cultural, desde a tomada de decisões corporativas até o marketing. (COULDRY, 2011: 488, tradução nossa)

A animação intitulada o voo nupcial é uma produção audiovisual amadora feita por sujeitos locais que apresentam o ritual da caça às tanajuras - é uma prática que surgiu com os índios Tabajaras, que foram os primeiros habitantes da região e permanece até os dias de hoje. Na animação é feita uma provocação para a comunidade, de como a ação do homem na natureza pode interferir no ciclo da tanajura. A produção audiovisual é disponibilizada no youtube e traz em seu roteiro a cultura dos moradores da região em uma prática ancestral que foi herdade dos índios Tabajaras - os primeiros habitantes da região da Ibiapaba que fica situada no noroeste do Ceará da qual Tianguá (CE) faz parte. 


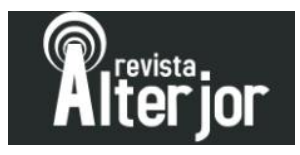

Produções como essa ganham espaços em sites, redes sociais digitais, jornais locais, a comunicação faz com que comunidade se sinta representada, que acesse e compartilha a mensagem, é o contato com sua história. Essas narrativas construídas por moradores da comunidade dão visibilidade, aproximam o sujeito de sua identidade cultural e transforma pautas locais em assuntos a serem debatidos em programas nacionais, a partir de ações como essa o consumo da tanajura em Tianguá (CE) já foi matéria no programa da Ana Maria Braga da Rede Globo de televisão.

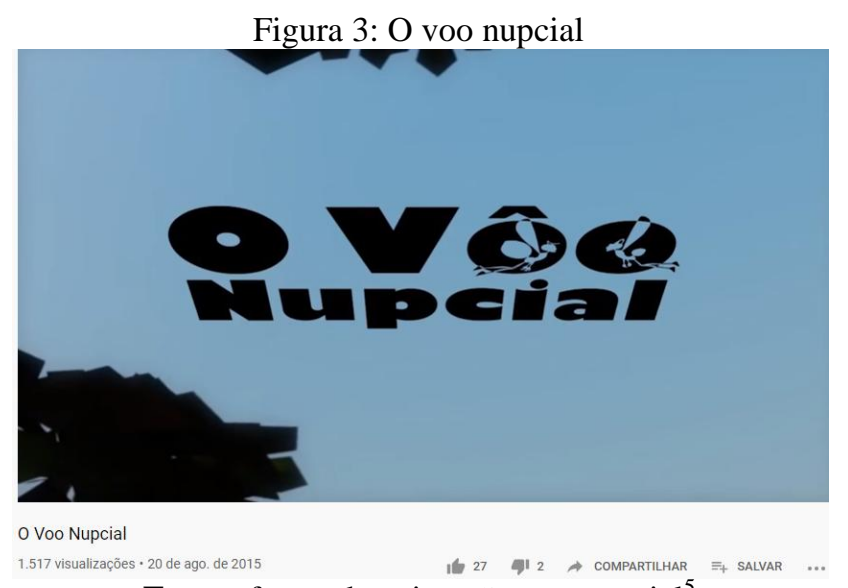

A fala da comunidade é muito importante, nos questionamos sobre a democratização da comunicação, tendo em vista que existe uma necessidade de trazer temáticas de culturas locais para as pautas em veículos de comunicação de caráter hegemônicos. Isso, nada mais é que tentar minimizar os preconceitos existentes que emergem a partir das diferenças culturais.

Ora, mesmo sem recursos e incentivos os sujeitos locais construíram esse projeto de animação 3D e participaram do VII edital de cinema e vídeo do Ceará. Os nativos produziriam uma narrativa que revelava um costume bastante comum na comunidade, $o$ consumo das tanajuras, de forma amadora, o trabalho teve a produção artística e cultural o nativo George Alex quem também assina como diretor da animação. E comenta (2010): Todo o trabalho de criação, modelagem e animação será realizado pela equipe

\footnotetext{
${ }^{5}$ Disponível em https://www.youtube.com/watch?v=77PcIIb0nAc. Acesso em 04/03/2020

Revista ALTERJOR

Grupo de Estudos Alterjor:Jornalismo Popular e Alternativo (ECA-USP)

Ano 10 Volume 02 Edição $22 \quad$ Juho- Dezembro de 2020

Avenida Professor Lúcio Martins Rodriģues, 443, Cidade Universitária, São Paulo, CEP: 05508-020
} 


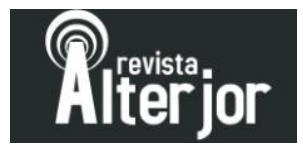

descrita acima e todo o restante do processo (trilha sonora, sonorização, montagem e finalização) será feito por artistas e técnicos da região. (ALEX, George, 2010, on-line).

O projeto de animação foi uma parceria com o também diretor e designer Natal Portela, que já conhecido na cidade por produzir filmes com temáticas locais, como a animação as aventuras de Chaga da onça, uma figura folclórica do município ser exagerado e o curta-metragem Francisca Carla que conta a história de uma empregada doméstica que foi isolada do convívio em sociedade em meados dos anos 40 por contrair uma doença popularmente conhecida como lepra, para o elenco desse filme, o diretor conseguiu de forma amigável atores conhecidos nacionalmente como Vinícius de Oliveira, Elke Maravilha e Ney Matogrosso.

Entretanto, com a ausência de políticas de comunicação somada a falta de leis e normas que orientem, auxiliem e regulamentem órgãos do governo em prol de sociedades mais justa e democrática, os veículos de comunicação de massa, principalmente os que pertencem aos grandes conglomerados midiáticos de uma forma geral precisam repensar suas pautas e desenvolver novos programas. Pois, a busca para promover lugar de fala não pode ficar somente nas mãos dos sujeitos locais ou das emissoras comunitárias, devem ser construídos espaços, como a criação de programas em veículos nacionais que promovam à diversidade cultural, para que possamos pensar em uma sociedade mais democrática, diversificada e multirrepresentada.

\section{CONSIDERAÇÕES FINAIS}

A mídia brasileira se construiu em um espaço nada democrático e ao longo dos anos foi se estabelecendo com moeda de troca entre políticos e grandes empresários. Sem querer entender que a comunicação é um direito de todos e democratizar seu acesso é uma questão central no campo da cidadania, os governos brasileiros não percebem que essas questões são sine qua non no desenvolvimento social e humano.

A importância da democratização da comunicação no Brasil parece não ser motivo de interesse dos governantes dessa nação. A ausência de uma legislação que minimize essa utopia entre comunidade e veículos de comunicação tem sido um campo fértil para os grandes conglomerados midiáticos. O poder de comunicar é algo que 


\section{Arejior}

precisa ser democratizado e as comunidades menores não pode se valer apenas dos meios digitais de comunicação.

Esse estudo apresenta elementos-chave para compreendermos a importância da comunicação em sua perspectiva sociocultural para uma sociedade com base nas práticas utilizadas na comunidade de Tianguá (CE). Neste artigo, questionamos a falta de políticas de comunicação e ausência de uma democracia no campo midiático brasileiro. Identificamos que na sociedade contemporânea a comunicação é mediatizada e atua em diferentes formatos o que pode promover uma mediação sociopolítica nas sociedades tecnologizadas.

Porém, a pesquisa não se esgota aqui, as políticas de comunicação carecem de estudos, tendo em vista que essa pauta ainda é pouco discutida e não existem muitas literaturas atuais abordando tais questões. A ideia é deixar os leitores instigados a promover ações que promovam debates e tragam as questões de comunicação e mídia para a agenda pública. O que pode ser feito, é trazer a comunicação para o debate do dia a dia, aproximar essa temática para as pautas locais sobre arte, educação, cultura, ocupando os mesmos espaços que discutem segurança, saúde, economia, entre outros.

\section{REFERÊNCIAS}

ANTÔNIO, Luís. Ícones da Ibiapaba: Vânia Vasconcelos - com diversos projetos culturais, escritora lançará trilogia sobre a tanajura - Parte 2. 2013. http://www.correioibiapaba.com.br/noticias/icones-da-ibiapaba-vania-vasconcelos-comdiversos-projetos-culturais-escritora-lancara-trilogia-sobre-a-tanajura-parte-2/

ALEX, George. Associação cultural garatuja. Animação 3d o vôo nupcial. 2010 http://associacaogaratuja.blogspot.com/2010/04/animacao-3d-o-vo-nupcial.html.

Acesso em: 11 de janeiro de 2020.

BORELLI, Sílvia H. S.; PRIOLLI, Gabriel (coords.). A deusa ferida: por que a Rede Globo não é mais a campeã absoluta de audiência. São Paulo: Summus, 2000.

BUCCI, Eugênio. Brasil em tempo de TV. São Paulo: Boitempo, 1996.

COULDRY, Nick. More sociology, more culture, more politics: or, a modest proposal for 'convergence' studies. In: Cultural Studies, vol. 25, n.4-5. Abingdon: Taylor \& Francis, 2011.

Revista ALTERJOR

Grupo de Estudos Alterjor: Jornalismo Popular e Alternativo (ECA-USP)

Ano 10 Volume 02 Edição $22 \quad$ Julho- Dezembro de 2020

Avenida Professor Lúcio Martins Rodrig̉ues, 443, Cidade Universitária, São Paulo, CEP: 05508-020 


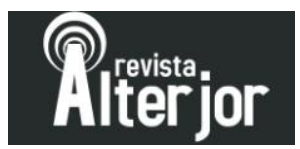

FÓRUM NACIONAL PELA DEMOCRATIZAÇÃO DA COMUNICAÇÃO (FNDC). Lei da Mídia Democrática. 2013. Disponível em: http:// http://consultapopular.org.br/noticia/campanha-para-expressar-liberdade . Acesso em: 19 de novembro de 2019.

GOMES, Pedro G. 1997. Comunicação Social: filosofia, ética, política. São Leopoldo: Ed. Unisinos.

HALL, Stuart. Quem precisa da Identidade? In: SILVA, Tomaz Tadeu da (org.), WOODWARD, Kathrin \& HALL, Stuart. Identidade e Diferença: a perspectiva dos estudos culturais. Rio de Janeiro: Vozes, 2014.

JENKINS, Henry. Cultura da Convergência. São Paulo: Aleph, 2008.

LARANJEIRA, Álvaro Nunes, CARDOSO, Moisés, KUMM Alexandre Artur Interações temporais na era da convergência: perspectivas das Gerações $\mathrm{Y}$ e $\mathrm{Z}$ nas redes sociais digitais. Revista Educação, Comunicação e Cultura - ECCOM. V. 7, n.14. 2016.

MCLUHAN, Marshall. Os meios de comunicação como extensões do homem. Rio de janeiro: Cultrix, 1964.

MEIO E MENSAGEM. Governo federal muda distribuição de verba nas emissoras de tv. Reportagem da folha baseada em relatório do tcu aponta que, diferente de outros anos, globo tem menos share de publicidade do governo do que record e sbt https://www.meioemensagem.com.br/home/midia/2019/11/12/governo-federal-mudadistribuicao-de-verba-nas-emissoras-de-tv.html. Acesso em: 10 de janeiro de 2020.

PIERANTI, Octavio. Políticas para a mídia: dos militares ao Governo Lula. In: Lua Nova, 68, 2006, pp. 91-121, Centro de Estudos de Cultura Contemporânea, s/d. Disponível em: http:// www.scielo.br/pdf/ln/n68/a04n68.pdf. Acesso em: 15 de agosto de 2013.

WOLTON, Dominique. Elogio do grande público. Uma teoria crítica da televisão. São Paulo: Editora Ática, 1996.

YODA, Carlos Gustavo. Convenção precisa dos movimentos sociais para partir para a práxis. In: Carta Maior. São Paulo, 28 de junho de 2007. Disponível em: https://www.cartamaior.com.br/?/Editoria/Midia/Convencao-precisa-dos-movimentossociais-para-partir-para-a-praxis/12/13598. Acesso em: 19 de novembro de 2019. 